\title{
Monitoring of Depth of Anesthesia using Entropy Monitor during Cardiopulmonary Bypass
}

\author{
${ }^{1}$ Pragya Sachan, ${ }^{2}$ Naina P Dalvi
}

\section{ABSTRACT}

Aim: To monitor the depth of anesthesia using entropy monitor during cardiopulmonary bypass (CPB) using (1) numerical indices provided by entropy monitor [response entropy (RE) and state entropy (SE), burst suppression ratio (BSR)] and (2) modified version of Brice questionnaire used after 48 hours of surgery.

Materials and methods: Design: Prospective observational study. Setting: Cardiovascular thoracic surgery (CVTS) operation theater (OT) of our hospital. Participants: 100 patients undergoing CPB surgery and willing to participate in the study. Intervention: Brain and facial muscular activity recorded using disposable sensor with three electrodes attached to patient's forehead and a sensor cable that connects the sensor to entropy module. Entropy indices were calculated and displayed in real time. All patients were then interviewed 48 hours after surgery about any recall of intraoperative awareness using the modified Brice questionnaire.

Measurements and results: Basic statistics was assessed by using MS Excel Office 2007 data analysis Tool Pack. The association between two variables was determined by Pearson chi-square test. After skin incision, mean RT and ST were found to decrease significantly till peak hypothermia. After start of rewarming, mean RT and ST were found to increase significantly till skin closure.

Conclusion: In our study, we did not find any awareness in all 100 studied subjects, leading to the conclusion that anesthesia technique used for CPB is optimal.

Clinical significance: It can be concluded that entropy monitor might aid CPB surgery in many ways. It monitors the depth of anesthesia and probably prevents intraoperative awareness, helps in reducing anesthetic dosage, and hence, reduction in cost of anesthesia.

Keywords: Cardiopulmonary bypass, Depth of anesthesia, Electroencephalogram-based monitors, Entropy, Monitoring.

\footnotetext{
${ }^{1}$ Specialist Medical Officer, ${ }^{2}$ Additional Professor

${ }^{1}$ Department of Anesthesia, Lokmanya Tilak Municipal General Hospital and Lokmanya Tilak Municipal Medical College Mumbai, Maharashtra, India

${ }^{2}$ Department of Anesthesia, Hinduhridaysamrat Balasaheb Thackeray Medical College and Dr. Rustom Narsi Cooper Municipal General Hospital, Mumbai, Maharashtra, India

Corresponding Author: Naina P Dalvi, Additional Professor Department of Anesthesia, Hinduhridaysamrat Balasaheb Thackeray Medical College and Dr. Rustom Narsi Cooper Municipal General Hospital, Mumbai, Maharashtra, India, Phone: +919820711656, e-mail: drnaina@rediffmail.com
}

How to cite this article: Sachan P, Dalvi NP. Monitoring of Depth of Anesthesia using Entropy Monitor during Cardiopulmonary Bypass. Res Inno in Anesth 2017;2(2):45-50.

\section{Source of support: Nil}

\section{Conflict of interest: None}

\section{INTRODUCTION}

General anesthesia is defined as the condition of loss of consciousness where patient is unresponsive to painful surgical stimuli. ${ }^{1}$ However, patients do recall various experiences during the surgery, known as "invisible scars of the surgery." The principle of entropy is that increasing depth of anesthesia causes increase in regularity of the electroencephalogram (EEG), which is then inferred by entropy and used to estimate the depth of anesthesia. During cardiac surgery, hemodynamic signs are less reliable guides to anesthetic depth, as most patients are heavily treated with beta-blockers and antihypertensives, and determining anesthetic depth during CPB is challenging.

\section{MATERIALS AND METHODS}

It was a prospective cross-sectional observational study. Following scientific research society and ethics committee approval, 100 patients undergoing CPB surgery and willing to participate in the study were included. Inclusion criteria were patients of either sex, aged 18 to 60 years, and consenting for monitoring.

Exclusion criteria were patients with history of neurological disorders including history of epilepsy, history of thromboembolic episodes related or unrelated to cardiac disease, and history of head injury.

The procedure of monitoring of depth of anesthesia using entropy monitor during $\mathrm{CPB}$ was performed in CVTS OT of our hospital. Patients who matched inclusion criteria were explained about the study and written informed consent was obtained. On the day of surgery, adequate starvation period was confirmed. Written valid consent was taken. After being taken on the operation table, a multiparameter monitor was connected to the patient. Patients' heart rate, blood pressure, and oxygen saturation were checked and noted. Brain and facial muscular activity was recorded using disposable sensor with three electrodes attached to patient's forehead and a 
sensor cable that connects the sensor to entropy module. Entropy indices were calculated and displayed in real time. All patients were then interviewed 48 hours after surgery about any recall of intraoperative awareness using the modified Brice questionnaire.

All patients received standard general anesthesia as per routine protocol. All patients were premedicated with Injection Fentanyl $2 \mu \mathrm{g} / \mathrm{kg}$ and promethazine $0.5 \mathrm{mg} / \mathrm{kg}$ intravenously. Then each patient was preoxygenated with $100 \% \mathrm{O}_{2}$ for 3 minutes. Anesthesia was induced with injection Midazolam $0.02 \mathrm{mg} / \mathrm{kg}+$ Fentanyl 4 to $5 \mu \mathrm{g} / \mathrm{kg}$ + Propofol till loss of consciousness. Neuromuscular blockade was achieved with injection Rocuronium $1 \mathrm{mg} / \mathrm{kg}$. Each patient was ventilated with $\mathrm{O}_{2}$ and $\mathrm{N}_{2} \mathrm{O}$ (50:50) for $2 \frac{1}{2}$ minutes followed by $100 \% \mathrm{O}_{2}$ for 30 seconds. Under direct laryngoscopic vision orotracheal intubation was done. Anesthesia was maintained with oxygen and air and Sevoflurane + Fentanyl infusion 5 to $10 \mu \mathrm{g} / \mathrm{kg} / \mathrm{hr}$ + Rocuronium infusion 0.45 to $0.6 \mathrm{mg} / \mathrm{kg} / \mathrm{hr}$.

Supplemental analgesia was provided with injection Fentanyl $1 \mu \mathrm{g} / \mathrm{kg}$ intravenously every hourly. Entropy indices were calculated and displayed in real time. The RE includes the frontal electromyogram and the SE evaluates only the cortical EEG. It provides numerical indices from 0 to 100 . The indices were manually recorded simultaneously every 1,2,3,5, 10 minutes and then every 15 minutes. Threshold value for adequate anesthesia was 40 to 60 for both S- and R-Entropy. Burst suppression ratio was monitored only when patient was too deep. In all patients, parameters like heart rate, $\mathrm{EtCO}_{2}$, temperature, and mean arterial pressures were recorded before and after induction and intubation. Mean arterial pressure, RE, SE, and temperature were recorded at each step of CPB.

All patients were then interviewed 48 hours after surgery about any memories or recall of intraoperative awareness using the modified Brice questionnaire.

\section{QUESTIONS USED TO ELICIT FREQUENCY OF RECALL}

- What was the last thing you remember before surgery?

- What is the first thing you remember once you woke up?

- Did you have any dream while you were asleep for surgery?

- Were you put to sleep gently?

- Did you have any problems going to sleep?

\section{Statistical Analysis}

The data were analyzed as mean \pm standard deviation (SD), frequency, and percentage as appropriate for the study. Basic statistics were assessed by using MS Excel
Office 2007 data analysis Tool Pack. For preparation of tables of frequency distribution and percentages, Statistical Package for the Social Sciences software (version 20) was used. Hemodynamic variables were analyzed by paired Student's t-test. The associations between two variables were determined by Pearson chisquare test. For all statistical comparisons in this study, a p-value $<0.05$ was considered to be significant and a p-value $<0.01$ was considered highly significant.

\section{RESULTS}

This prospective observational study included 100 adult patients who underwent CPB surgeries operated by a cardiovascular surgical team over a period of $1 \frac{1}{2}$ years. Following observations were made.

\section{Demographic Data}

- The age of all 100 patients was between 19 and 60 years with average of $40.75 \pm 11.53$ years.

- $49.0 \%$ of cases were male and $51.0 \%$ of cases were female.

- The average weight of patients was $59.78 \pm 9.69 \mathrm{~kg}$ ranging from 39 to $84 \mathrm{~kg}$.

- The average height of cases was $159.96 \pm 7.84 \mathrm{~cm}$ ranging from 146 to $178 \mathrm{~cm}$.

- Body surface area (BSA) of cases ranged from 1.35 to $1.99 \mathrm{~kg} / \mathrm{m}^{2}$ with average of $1.61 \pm 0.16 \mathrm{~kg} / \mathrm{m}^{2}$ among study cases (Table 1).

\section{Change in Mean RE from Induction}

- According to this study, at table, mean RE was 64.40 .

Table 1: Demographic data

\begin{tabular}{ll}
\hline Parameters & Percentage \\
\hline No. of cases & 100 \\
Age (years) & \\
Mean & 40.75 \\
SD & 11.53 \\
Range & $19-60$ \\
Sex (\%) & \\
Male & $49(49.0 \%)$ \\
Female & $51(51.0 \%)$ \\
Weight $(\mathrm{kg})$ & \\
Mean & 59.78 \\
SD & 09.69 \\
Range & $39-84$ \\
Height $(\mathrm{cm})$ & \\
Mean & 159.96 \\
SD & 07.84 \\
Range & $146-178$ \\
BSA $\left(\mathrm{kg} / \mathrm{m}^{2}\right)$ & \\
Mean & 1.61 \\
SD & 0.16 \\
Range & $1.35-1.99$ \\
\hline
\end{tabular}


Monitoring of Depth of Anesthesia using Entropy Monitor

Table 2: Change in mean RE from induction

\begin{tabular}{ll}
\hline Steps of CPB & Mean RE $(\bar{X} \pm S D)(n=100)$ \\
\hline On table & $64.40 \pm 12.46$ \\
Immediate postinduction (T0) & $63.03 \pm 11.02$ \\
Skin incision (T1) & $59.73 \pm 12.62^{*}$ \\
Sternotomy (T2) & $57.53 \pm 14.75^{*}$ \\
Aortic cannulation (T3) & $51.21 \pm 14.09^{*}$ \\
Venous/RA cannulation (T4) & $49.30 \pm 13.28^{*}$ \\
Beginning of CPB (T5) & $45.08 \pm 11.16^{*}$ \\
Start of hypothermia (T6) & $40.65 \pm 10.23^{*}$ \\
Peak hypothermia (T7) & $36.99 \pm 00.53^{*}$ \\
Start of rewarming (T8) & $41.77 \pm 10.90^{*}$ \\
Complete rewarming (T9) & $47.83 \pm 12.31^{*}$ \\
Off bypass (T10) & $54.59 \pm 13.44^{*}$ \\
At protamine injection (T11) & $55.28 \pm 14.58^{*}$ \\
Closure of sternal wire (T12) & $58.55 \pm 14.22^{*}$ \\
Skin closure (T13) & $55.96 \pm 13.50^{*}$ \\
\hline
\end{tabular}

Student's t-test, $p<0.05$, *Significant; RA: Right atrium

- After skin incision (T1), mean RE was 59.73, which decreased significantly till peak hypothermia (T7).

- After start of rewarming (T8), mean RE was 41.77, which increased significantly from peak hypothermia till skin closure (T13) (Table 2).

\section{Change in Mean SE from Induction}

- On table, mean SE was 60.92.

- After skin incision (T1), mean SE was 56.51, which significantly decreased till peak hypothermia (T7).

- After start of rewarming (T8), mean SE was 38.71, which increased significantly from peak hypothermia till skin closure (T13). But all these levels were significantly less as compared with baseline (Table 3 and Graph 1).
Table 3: Change in mean SE from induction

\begin{tabular}{ll}
\hline Induction & Mean SE $(\bar{X} \pm S D)(n=100)$ \\
\hline On table & $60.92 \pm 12.68$ \\
Immediate postinduction (T0) & $60.30 \pm 11.05$ \\
Skin incision (T1) & $56.51 \pm 12.51^{*}$ \\
Sternotomy (T2) & $54.57 \pm 13.98^{*}$ \\
Aortic cannulation (T3) & $48.06 \pm 13.52^{*}$ \\
Venous/RA cannulation (T4) & $46.05 \pm 13.24^{*}$ \\
Beginning of CPB (T5) & $42.07 \pm 11.00^{*}$ \\
Start of hypothermia (T6) & $37.78 \pm 10.10^{*}$ \\
Peak hypothermia (T7) & $34.26 \pm 09.78^{*}$ \\
Start of rewarming (T8) & $38.71 \pm 10.07^{*}$ \\
Complete rewarming (T9) & $44.75 \pm 11.72^{*}$ \\
Off bypass (T10) & $51.20 \pm 12.60^{*}$ \\
At protamine injection (T11) & $51.64 \pm 13.84^{*}$ \\
Closure of sternal wire (T12) & $55.23 \pm 13.73^{*}$ \\
Skin closure (T13) & $53.10 \pm 12.67^{*}$ \\
\hline
\end{tabular}

Student's t-test, $p<0.05$, *Significant; RA: Right atrium

\section{Hemodynamic Monitoring during Pre- and Post-bypass Period}

\section{Mean Pulse Rate and Mean Pressure during} Pre- and Post-bypass Period

- As per this study, at immediate postinduction (T0) mean pressure was $84.00 \pm 8.55 \mathrm{~mm} \mathrm{Hg}$.

- After aortic cannulation (T3), mean pressure was 77.35 $\pm 9.96 \mathrm{~mm} \mathrm{Hg}$, which decreased significantly till skin closure (T13) (Table 4).

\section{Mean $\mathrm{EtCO}_{2}, \mathrm{CVP}$, and Temperature in Pre- and Post-bypass Period}

- $\mathrm{SpO}_{2}$ in all patients did not show any statistical significant changes during pre- and post-bypass period (mean $\mathrm{SpO}_{2}$ was $99.00 \pm 0.00 \%$ ).

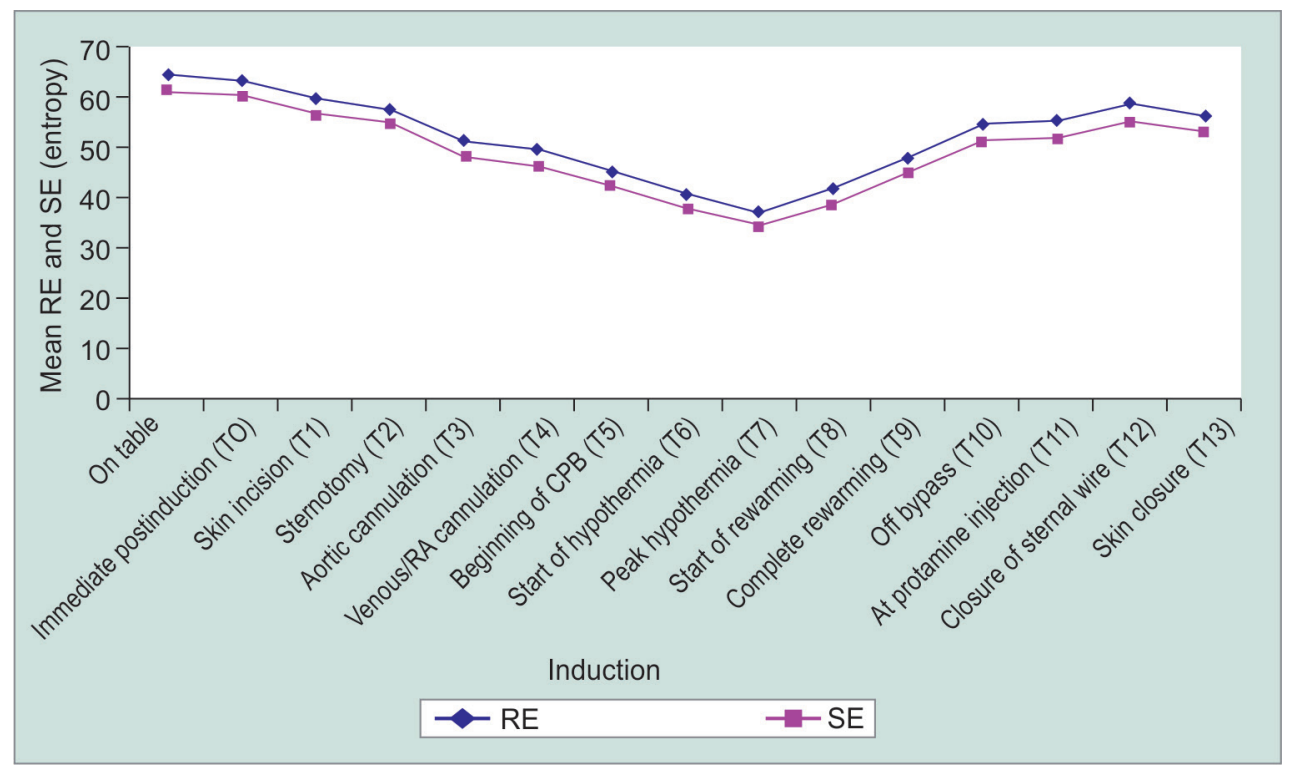

Graph 1: Change in mean RE and SE from induction 
Table 4: Mean pulse rate and mean pressure during pre- and post-bypass period

\begin{tabular}{|c|c|c|}
\hline Induction & $\begin{array}{l}\text { Mean pulse rate } \\
(/ \min )(\bar{X} \pm S D) \\
(n=100)\end{array}$ & $\begin{array}{l}\text { Mean pressure } \\
(m m H g)(\bar{X} \pm S D) \\
(n=100)\end{array}$ \\
\hline $\begin{array}{l}\text { Immediate postinduction } \\
\text { (T0) }\end{array}$ & $103.20 \pm 14.28$ & $84.00 \pm 08.55$ \\
\hline Skin incision (T1) & $100.80 \pm 12.15$ & $83.41 \pm 07.81$ \\
\hline Sternotomy (T2) & $98.15 \pm 09.19^{*}$ & $82.01 \pm 08.66$ \\
\hline Aortic cannulation (T3) & $96.10 \pm 08.18^{*}$ & $77.35 \pm 09.96^{*}$ \\
\hline Venous/RA cannulation (T4) & $98.64 \pm 09.14^{*}$ & $74.12 \pm 09.88^{*}$ \\
\hline At protamine injection (T11) & $98.77 \pm 11.31^{*}$ & $71.06 \pm 08.41^{*}$ \\
\hline Closure of sternal wire (T12) & $101.22 \pm 09.96$ & $73.45 \pm 07.34^{*}$ \\
\hline Skin closure (T13) & $98.05 \pm 11.93^{*}$ & $76.10 \pm 07.26^{*}$ \\
\hline
\end{tabular}

- Above table reveals that at immediate postinduction $\left(\mathrm{T}_{0}\right)$ mean central venous pressure $(\mathrm{CVP})$ was $10.67 \pm$ $0.92 \mathrm{~cm} \mathrm{H}_{2} \mathrm{O}$.

- After skin closure (T13), mean CVP was $10.68 \pm 1.02 \mathrm{~cm}$ $\mathrm{H}_{2} \mathrm{O}$, which increased from closure of sternal wire (T12) (Table 5).

\section{DISCUSSION}

Awareness during general anesthesia was observed even in the very first patients who were anesthetized. ${ }^{1,2}$ As per a multicenter study in the United States held in 2004, the frequency of intraanesthetic awareness was found to be $0.13 \%$, with more frequent occurrence in high-risk groups (obstetric, cardiac, and airway surgery), as well as during anesthesia in children. ${ }^{3}$

The present study was conducted to monitor depth of anesthesia during CPB using entropy monitor. We also attempted to find out the possible incidence of awareness during CBP.

It is desirable to monitor depth of anesthesia during all the surgeries, especially during cardiac surgeries, where hemodynamic signs are less reliable guide to anesthetic depth, as most patients are heavily treated with betablocking drugs and antihypertensive medication. Also, $\mathrm{CPB}$ with variable degree of hypothermia and increased volume of distribution presents an even more complex situation.

Depth of anesthesia is usually estimated by the anesthesiologist according to autonomic response. Sudden hypertension and/or tachycardia, sweating, tearing may indicate lightening of anesthesia. However, other events like hypotension, dehydration, hypoxia, hypoor hyperthermia, sudden massive blood loss, etc., may also lead to such hemodynamic changes. Factors, such as cardiac drugs like beta-blockers, antihypertensive drugs, inotropes, and vasodilators may also affect blood pressure and heart rate. Patient response to surgical stimulus score, based on autonomic changes in response to surgical
Table 5: Mean $\mathrm{EtCO}_{2}, \mathrm{CVP}$, and temperature in pre- and post-bypass period

\begin{tabular}{|c|c|c|c|}
\hline Induction & $\begin{array}{l}\text { Mean CVP } \\
(\bar{X} \pm S D) \\
(n=100)\end{array}$ & $\begin{array}{l}\text { Mean } \mathrm{EtCO}_{2} \\
(\bar{X} \pm S D) \\
(n=100)\end{array}$ & $\begin{array}{l}\text { Mean } \\
\text { temperature } \\
\left({ }^{\circ} \mathrm{C}\right)(\bar{X} \pm S D) \\
(n=100)\end{array}$ \\
\hline $\begin{array}{l}\text { Immediate } \\
\text { postinduction (TO) }\end{array}$ & $10.67 \pm 0.92$ & $35.71 \pm 1.12$ & $36.48 \pm 0.33$ \\
\hline Skin incision (T1) & $10.47 \pm 1.11$ & $35.95 \pm 1.40$ & $36.41 \pm 0.42$ \\
\hline Sternotomy (T2) & $10.65 \pm 1.06$ & $36.10 \pm 1.25^{*}$ & $36.02 \pm 0.43^{*}$ \\
\hline $\begin{array}{l}\text { Aortic cannulation } \\
\text { (T3) }\end{array}$ & $10.42 \pm 1.18$ & $35.86 \pm 1.50$ & $35.86 \pm 0.41^{*}$ \\
\hline $\begin{array}{l}\text { Venous/RA } \\
\text { cannulation (T4) }\end{array}$ & $10.41 \pm 1.29$ & $35.83 \pm 1.44$ & $35.61 \pm 0.45^{*}$ \\
\hline $\begin{array}{l}\text { At protamine } \\
\text { injection (T11) }\end{array}$ & $10.38 \pm 1.31$ & $35.71 \pm 1.46$ & $36.35 \pm 0.35^{*}$ \\
\hline $\begin{array}{l}\text { Closure of sternal } \\
\text { wire (T12) }\end{array}$ & $10.17 \pm 1.28^{*}$ & $35.72 \pm 1.63$ & $36.28 \pm 0.47^{*}$ \\
\hline Skin closure (T13) & $10.68 \pm 1.02$ & $36.26 \pm 1.26^{*}$ & $36.54 \pm 0.44$ \\
\hline
\end{tabular}

Student's t-test, $p<0.05$, ${ }^{\star}$ Significant; RA: Right atrium

stimulus, is a poor indicator of depth of anesthesia. ${ }^{4}$ It has been proven that hemodynamic responsiveness to noxious stimuli does not necessarily signify awareness, nor does lack of hemodynamic changes guarantee unconsciousness.

In the present study, a disposable sensor with three electrodes is attached to the patients' forehead to record brain and facial muscular activity and a sensor cable connects this sensor to the entropy module. Entropy indices are calculated and displayed in real time, the RE that includes the frontal electromyogram and the SE that evaluates only the cortical EEG. It provides numerical indices from 0 to 100 .

Several investigators have compared spectral entropy parameters with bispectral index (BIS) using different anesthetic drugs during the period of induction of anesthesia but their results were inconsistent. Baulig et $\mathrm{al}^{5}$ compared spectral entropy and BIS electroencephalography in coronary artery bypass graft (CABG) surgery. The comparability of RE and SE and BIS was investigated during the period of maintenance of the propofol-remifentanil anesthesia in which the remifentanil concentration was kept constant and fentanyl was added at expected painful periods. The findings of the study suggested that entropy values were comparable with the BIS but showed significantly less resistance against artifacts, leading to the conclusion that entropy is more suitable than BIS during anesthesia in cardiac surgery patients. Thus, strong correlation between BIS and spectral entropy parameters was found in their investigation.

White et $\mathrm{al}^{6}$ reported a good correlation between SE and BIS during induction and maintenance of anesthesia with propofol and desflurane in patients undergoing major laparoscopic surgery. In their study, 
changes in RE and SE compared favorably with those in the BIS during the perioperative period. Hence, it was concluded that the entropy module is a cost-equivalent alternative to the BIS monitor.

Very few studies have been done where only entropy is used for monitoring anesthetic depth during CPB.

Sinha et $\mathrm{al}^{7}$ did a retrospective study of 33 cases that were monitored with BIS during coronary artery or valvular surgery, including the period of $\mathrm{CPB}$. It was found that the value of BIS which was ranging between 40 and 60 after induction dropped below 25 at the onset of CPB.

In our study, real-time processed EEG signal monitoring entropy showed a marked drop in electrical activity at the onset of CPB. After skin incision (T1), mean RE was $59.73 \pm 12.62$, which significantly decreased till peak hypothermia (T7). After start of rewarming (T8), mean RE was $41.77 \pm 10.90$, which significantly increased from peak hypothermia till skin closure (T13). There was statistically significant fall in all these levels as compared with baseline.

After skin incision (T1), mean SE was $56.51 \pm 12.51$, which significantly decreased till peak hypothermia (T7). After start of rewarming (T8), mean SE was 38.71 \pm 10.07 , which significantly increased from peak hypothermia till skin closure (T13). The SE level was also significantly less as compared with baseline.

Reduced EEG signal from the brain may result from increasing depth of anesthesia but it may also result from other causes of decreased neuronal activity, such as hypoxia.

Due to concern of myocardial depression during CPB surgery, many anesthesiologists prefer to reduce the dosage of anesthetic drugs. Many studies have shown that it was possible that patients anesthetized using routine clinical signs received more anesthesia than necessary when entropy was not used for monitoring. Due to entropy monitoring, the reduction of anesthetic drugs during CPB surgery can lead to less myocardial depression, less decrease in system vascular resistance, and less need for inotropic support.

With respect to change in temperature during $\mathrm{CPB}$, after start of hypothermia (T6), mean temperature was $35.06 \pm 0.52^{\circ} \mathrm{C}$, which significantly decreased till start of rewarming (T8). After complete rewarming (T9), mean temperature was $36.74 \pm 0.44^{\circ} \mathrm{C}$, which significantly increased from start of rewarming (T8) till off bypass (T10). Therefore, as temperature decreases, mean RE and SE also decrease. There is a definite correlation of temperature and level of anesthesia, possibly due to increased duration of action of drugs due to decreased basal metabolic rate. In our study, BSR has been found to be 0 in all 100 patients studied, indicating that the depth of anesthesia was never too deep in all the 100 subjects nor was there any incidence of neurological complications in the studied subjects.

The Brice questionnaire is acknowledged to be the accepted tool for detecting awareness postoperatively. We chose to use the modified version of Brice questionnaire. This open-ended questioning technique has been previously described by Fleisher et al. ${ }^{8}$

Siddiqi et $\mathrm{al}^{9}$ in their study of 100 patients undergoing elective $C A B G$ found a slightly higher frequency of awareness (5\%). Patients were interviewed 24 to 72 hours after anesthesia using a modified Brice questionnaire. In their study, awareness was found to be less in patients who received propofol infusion during $\mathrm{CPB}$ compared with the patients who did not.

In our patients, we conducted the interview only once, 48 hours after the surgery. None of the patients in our study reported any awareness. Thus, after studying 100 cases undergoing CPB in our institute, it has been found that both RE and SE were maintained within acceptable range in all patients. Also, there was lack of awareness in all the 100 patients interviewed postoperatively. Hence, it can be concluded that the anesthesia technique used for CPB in our institute was adequate to maintain depth of anesthesia intraoperatively, during pre-, post-, and on CPB period.

An incidence of awareness of 0.3 to $2.3 \%$ in patients undergoing cardiac surgery has been reported. Although none of the patients in our study reported intraoperative recall, a much larger study population would be required to detect whether entropy could help to decrease intraoperative awareness in patients undergoing CPB surgery.

Thus, considerable number of studies has to be undertaken with larger number of subjects in each study. Entropy has been found to be very helpful in early diagnosis of awareness during anesthesia as well as in early diagnosis of intraoperative neurological complications, which can thereby guide us in modulating anesthesia technique. The study subject itself draws attention to an often-neglected area and is clinically relevant with scope for change in practice in the future.

\section{REFERENCES}

1. Osterman JE, van der Kolk BA. Awareness during anaesthesia and posttraumatic stress disorder. Gen Hosp Psychiatry 1998 Oct;20:274-281.

2. Simini B. Awareness of awareness during general anaesthesia. Lancet 2000 Feb;355(9205):672-674.

3. Sebel PS, Bowdle TA, Ghoneim MM, Rampil IJ, Padilla RE, Gan TJ, Domino KB. The incidence of awareness during anaesthesia: a multicentre united states study. Anesth Analg 2004 Sep;99(3):833-839.

4. Evans JM, Davies WL. Monitoring anaesthesia. Clin Anesth 1984;2:243-262. 
5. Baulig W, Seifert B, Schmid ER, Schwarz U. Comparison of spectral entropy and bispectral index electroencephalography in coronary artery bypass graft surgery. J Cardiothorac Vasc Anesth 2010 Aug;24(4):544-549.

6. WhitePF, TangJ, Romero GF, Wender RH,Naruse R, Sloninsky A, Kariger R. A comparison of state and response entropy versus bispectral index values during the perioperative period. Anesth Analg 2006 Jan;102(1):160-167.
7. Sinha A, Ramesh GS, Singh VP. Changes in Bispectral Index (BIS) values during Cardiopulmonary Bypass (CPB). Med J Armed Force India 2011 Jan;67(1):38-40.

8. Fleischer LH, Glass PSA. Evidence based practice of anesthesiology: can we prevent recall during anesthesia? Philadelphia (PA), WB Saunders; 2004. pp. 223-227

9. Siddiqi R, Naqvi S, Abbas S, Bakhsh M, Ahmed I. Awareness during coronary artery bypass grafting surgery. . Pak Armed Forces Med J 2011 Dec;61(4). 